\title{
UMA PROPOSTA DIDÁTICA PARA O ENSINO DO TEOREMA DE PITÁGORAS
}

\section{A DIDACTIC PROPOSAL FOR TEACHING THE PYTHAGORAS' THEOREM}

\author{
Cecília de Souza Fernandez ${ }^{1}$ \\ Weverton Magno Ferreira de Castro ${ }^{2}$
}

\begin{abstract}
RESUMO: O teorema de Pitágoras é um resultado matemático muito lembrado por aqueles que o estudaram na escola básica. Contudo, poucos conhecem a história desse teorema e a história de Pitágoras de Samos, assim como algumas demonstrações desse resultado. Nossa proposta se baseia no uso da história da Matemática para motivar os alunos ao estudo do tema. De fato, segundo a MAA (Mathematical Association of America), o conhecimento da história da Matemática mostra aos alunos que ela é uma importante conquista humana, geralmente desenvolvida de forma intuitiva e experimental a partir da necessidade de se resolver problemas nas mais diversas áreas do saber. Por acreditar que também é relevante mostrar aos alunos que em Matemática é importante se demonstrar os resultados, já que a Matemática não deve ser vista como uma coleção de fórmulas que devem ser memorizadas, apresentamos algumas demonstrações que podem ser feitas com os alunos.
\end{abstract}

PALAVRAS-CHAVE: Teorema de Pitágoras, História da Matemática, Demonstração, Ensino.

ABSTRACT: Pythagoras' theorem is a mathematical result that is well remembered by those who studied it in elementary school. However, few remember the history of this theorem and the history of Pythagoras of Samos, as well as some known demonstrations of this result. Our proposal is based on the use of the history of Mathematics to motivate students to study the subject. In fact, according to the MAA (Mathematical Association of America), the knowledgement of the history of Mathematics shows students that it is an important human achievement, usually developed in an intuitive and experimental way from the need to solve problems in different areas. Because of the belief that it is also important to show students that in Mathematics it is important to demonstrate results, since Mathematics should not be seen as a collection of formulas that should be memorized, we present some demonstrations that can be done with students.

KEYWORDS: Pythagoras Theorem, History of Mathematics, Proof, Teaching.

\section{Introdução}

Toda pessoa que já passou por alguma escola e concluiu o ensino fundamental, certamente já ouviu falar de Pitágoras. O teorema que leva seu nome também é bastante conhecido, assim como suas aplicações no mundo real.

\footnotetext{
1 Universidade Federal Fluminense. E-mail: ceciliafernandez@id.uff.br

(i) https://orcid.org/0000-0001-6410-5117

2 Instituto Federal de Educação, Ciência e Tecnologia do Rio de Janeiro. E-mail: weverton.castro@ifrj.edu.br

(1D) https://orcid.org/0000-0002-5849-9305

- Informações completas da obra no final do artigo
} 
No presente trabalho apresentar-se-á um pouco sobre a história do teorema de Pitágoras e sobre o próprio Pitágoras, considerado por muitos especialistas em História da Matemática como o primeiro matemático. Onde ele nasceu, como conheceu a Matemática e, finalmente, como fundou o que se conhece como "escola pitagórica" ou "irmandade pitagórica".

Enuncia-se o teorema de Pitágoras e apresenta-se um pouco sobre sua história. Cinco demonstrações distintas deste teorema são desenvolvidas, propiciando um contato direto com diferentes maneiras de se conhecer tal teorema. Uma parte importante deste trabalho é a proposta didática para o desenvolvimento do tema nos ensinos fundamental e médio é também apresentada.

Por fim, neste trabalho, denota-se $\overline{A B}$ como segmento que possui extremidades nos pontos $A$ e $B$. E a medida do segmento $\overline{A B}$ como $A B$.

\section{Pitágoras e a escola pitagórica}

Considerado o primeiro matemático, Pitágoras nasceu no século VI a.C. em Samos, uma das ilhas do Dodecaneso (um grupo de ilhas gregas na extremidade leste do Mar Egeu, junto à costa sudoeste da Turquia), próximo a Mileto, lugar de nascimento de Tales. Não há como precisar o ano de nascimento de Pitágoras. Algumas fontes afirmam que foi por volta de 550 a.C. ou 569 a.C..

Com idade próxima a 18 ou 19 anos, Pitágoras partiu de Samos para conhecer o mundo, pois, em sua época, isto era um costume para adquirir conhecimento através do contato com outros povos. Nestas viagens, Pitágoras visitou e viveu alguns anos no Egito e Babilônia e é muito provável que ele tenha ido também a Índia. Contemporâneo de Confúcio, Lao-Tse e Buda, há quem diga que Pitágoras teve contato com Buda e seus ensinamentos em sua provável passagem pela Índia.

\footnotetext{
Pitágoras adquiriu suas habilidades matemáticas em suas viagens pelo mundo antigo. Algumas histórias tentam nos fazer crer que Pitágoras teria ido até a Índia e a Inglaterra, mas o mais certo é que ele aprendeu muitas técnicas matemáticas com os egípcios e os babilônicos. Esses povos antigos tinham ido além da simples contagem e eram capazes de cálculos complexos que lhes permitiam criar sistemas de contabilidade sofisticados e construir prédios elaborados. De fato, os dois povos viam a matemática como uma ferramenta para resolver problemas práticos. A motivação que conduziu à descoberta de algumas das leis básicas da geometria era a necessidade de refazer a demarcação dos campos, perdida durante as enchentes anuais do Nilo. A palavra geometria significa "a medida da terra" (SINGH, 2008, p. 29).
} 
É desta situação gerada pelas enchentes anuais do rio Nilo que os antigos egípcios desenvolveram métodos usando cordas para refazerem na terra as marcações apagadas pelo rio. Um desses métodos, que é bastante interessante, era utilizar uma corda aberta com 13 nós, igualmente espaçados, para construir um triângulo com lados medindo $3,4 \mathrm{e}$ 5. Os egípcios perceberam que com tal triângulo era possível construir um ângulo reto entre os lados que mediam 3 e 4 . Ou seja, eles conheciam pelo menos um terno de números ditos pitagóricos, que com certeza não eram ainda conhecidos desta forma. Mas, mesmo sem qualquer documento que comprove isto, o mais importante é que estas situações devem ter sido vividas de alguma forma por Pitágoras nestas viagens.

Voltando à Grécia, Pitágoras tinha o objetivo de fundar uma escola para estudar a filosofia e a matemática que aprendeu durante suas viagens por estes diferentes povos. Porém, em Samos, Pitágoras enfrentou um problema político. Durante suas viagens, um tirano persa, chamado Polícrates, teria transformado Samos em uma cidade conservadora, um lugar de intolerância. Convidado por Polícrates para compor a equipe de sua corte, Pitágoras percebeu que esta era a maneira encontrada para fiscalizá-lo, impedindo que ele difundisse a ideia do estudo filosófico e matemático. A princípio, a solução encontrada por Pitágoras foi se refugiar em uma caverna localizada em uma região remota da ilha, a fim de continuar seus estudos.

Pitágoras não apreciava o isolamento e acabou subornando um menino para ser
seu primeiro aluno. A identidade do garoto é incerta, mas alguns historiadores
sugerem que ele também se chamaria Pitágoras [...] Pitágoras, o mestre, pagava
ao seu aluno três ébolos para cada aula a que ele comparecia. Logo percebeu que,
à medida que as semanas se passavam, a relutância inicial do menino em aprender
se transformava em entusiasmo pelo conhecimento. Para testar seu pupilo,
Pitágoras fingiu que não podia mais pagar o estudante e que teria de interromper
as aulas. Então o menino se ofereceu para pagar por sua educação. O pupilo
tornara-se discípulo. Infelizmente este foi o único adepto que Pitágoras conquistou
em Samos. Ele chegou a estabelecer temporariamente uma escola conhecida como
o Semicírculo de Pitágoras, mas suas ideias de reforma social eram inaceitáveis e
o filósofo foi obrigado a fugir com sua mãe e seu único discípulo (SINGH, 2008, p.
30).

Foi neste momento que Pitágoras chega a Crotona, uma antiga cidade-estado da Magna Grécia, onde hoje é o sul da Itália. Por lá, Pitágoras encontrou o apoio de Milo, que era o homem mais rico e forte da cidade. Além de influente politicamente, Milo era forte fisicamente, já que era um atleta olímpico, cinco vezes campeão de luta livre nos jogos olímpicos da antiguidade. Este homem já tinha ouvido sobre a fama de Pitágoras, que 
ecoava na Grécia, e lhe cedeu parte de sua casa para que Pitágoras fundasse a sua escola, tendo inclusive a filha de Milo, uma bela mulher chamada Teano, como uma de suas alunas. Futuramente, apesar da diferença de idade, Pitágoras e Teano acabaram se casando.

É então que nasce a famosa "escola pitagórica", conhecida também como "irmandade pitagórica", já que esta escola possuía também um caráter religioso e era cercada de mistérios e lendas.

Talvez Pitágoras, influenciado pelas tradições budistas, desenvolveu a ideia de comunidade fraternal (sangha - comunidade dos budistas que têm os mesmos objetivos). Com características monásticas, instituiu ritos de abstinência, pureza e o vegetarianismo, que era imposto ou aceito pelos que queriam participar da escola (CYRINO, 2006, p. 38).

Estes são relatos de algumas histórias que cercavam a escola pitagórica. O fato é que tal escola contava com cerca de seiscentos seguidores que estudavam e desenvolviam a matemática proposta por Pitágoras. O interesse deles era de ir além da utilização dos números. Eles queriam entendê-los profundamente, tanto que o lema da escola pitagórica é que "tudo é número".

Pitágoras desenvolveu a idéia da lógica numérica e foi responsável pela primeira idade de ouro da matemática. Graças ao seu gênio, os números deixaram de ser apenas coisas usadas meramente para contar e calcular e passaram a ser apreciados por suas próprias características. Ele estudou as propriedades de certos números, o relacionamento entre eles e os padrões que formavam. Ele percebeu que os números existem independentemente do mundo palpável e, portanto, seu estudo não é prejudicado pelas incertezas da percepção (SINGH, 2008, p. 28).

Além de entender completamente o que cada número significava e de estudar a relação entre eles, a irmandade pitagórica cercava os números de imenso misticismo. A partir deste raciocínio, os pitagóricos chegaram a listar as características místicas dos primeiros números naturais. O número "um" é o gerador dos números, o primeiro número masculino. O "dois" que é o primeiro dos números femininos, o número da opinião. "Três" é o número da harmonia ou número da forma, por causa das dimensões: comprimento, largura e altura. O número "quatro" se corresponde ao tetraedro onde as faces seriam os elementos ar, terra, fogo e água. A soma do primeiro número feminino com o primeiro número masculino verdadeiro, respectivamente 2 e 3 , chegaria ao "cinco" que, por isso, é o número do casamento. O "seis" é o número da criação. "Sete" é a junção da harmonia, simbolizada pelo 3, com os elementos, que é o 4 . Sendo o dobro do número que representa os elementos, o "oito" é o número das formas perfeitas. Já o número "nove" é a 
caracterização numérica da indestrutibilidade, pois a soma dos algarismos de seus múltiplos é ele próprio; exemplos: 18, 27 e 36. E o "dez" é o número sagrado.

Mas a escola formada por Pitágoras descobriu propriedades interessantes em alguns números. Para Pitágoras, a perfeição de um número era demonstrada utilizando de seus divisores próprios. Quando um número inteiro possuía divisores próprios cuja soma era menor que o próprio número ele, o chamava de "número deficiente". Um exemplo é o 10. Seus divisores próprios (1, 2 e 5) possuem soma igual a 8 que é menor que o 10. Já quando a soma dos divisores próprios de um número era maior que o mesmo, ele recebia o nome de "número abundante" ou "número excessivo". O número 20 é um exemplo. Seus divisores próprios (1, 2, 4, 5 e 10) possuem soma igual a 22 que é maior do que o 20. Porém, quando a soma dos divisores próprios de um número é exatamente igual ao mesmo, ele é chamado de "número perfeito". O primeiro número perfeito é o 6 , pois seus divisores próprios são 1, 2 e 3 cuja soma é 6 . Um fato curioso é que a irmandade pitagórica acreditava que Deus criou o mundo em seis dias, porque este é o número perfeito. E que se Deus não tivesse feito desta forma, o seis continuaria a ser perfeito.

Os primeiros números perfeitos são 6, 28, 496 e 8128 . Note que fica cada vez mais difícil encontrá-los usando este método dos divisores. Foi desta dificuldade que Pitágoras tentou desenvolver outro método para encontrá-los. A sua crença era que o número 2 estava ligado a perfeição dos números. Foi quando ele descobriu que as potências de 2 que podem ser escritas como $2^{n}$, com $n$ natural, chegavam próximas a perfeição. Isto porque, dado um $n_{0}$ natural, a soma dos divisores próprios de $2^{n_{0}}$ é sempre $2^{n_{0}}-1$. Por exemplo,

a) $2^{2}=4$ e seus divisores próprios ( 1 e 2) possuem soma igual a 3 ;

b) $2^{3}=8$ e seus divisores próprios (1, 2 e 4) possuem soma igual a 7;

c) $2^{4}=16$ e seus divisores próprios (1, 2, 4 e 8) possuem soma igual a 15 .

Pitágoras não estava totalmente errado em sua suspeita. Algum tempo depois Euclides descobriria, provavelmente baseado no raciocínio de Pitágoras, que os números da forma $2^{n-1} \cdot\left(2^{n}-1\right)$, para algum $n$ natural, são perfeitos. Por exemplo,
a) Para $n=2,2^{1} \cdot\left(2^{2}-1\right)=2 \cdot 3=6$;
b) Para $n=3,2^{2} \cdot\left(2^{3}-1\right)=4 \cdot 7=28$; 
C) Para $n=5,2^{4} \cdot\left(2^{5}-1\right)=16 \cdot 31=496$;

d) Para $n=7,2^{6} \cdot\left(2^{7}-1\right)=64 \cdot 127=8128$.

Para que o número da forma $2^{n-1} \cdot\left(2^{n}-1\right)$ seja perfeito, se faz necessário que o número $2^{n}-1$ seja um número primo de Mersenne. Como, até a data de publicação deste trabalho, eram conhecidos 51 números primos de Mersenne. Então, existem 51 números perfeitos, sendo o maior deles o número $2^{82589932}\left(2^{82589933}-1\right)$ descoberto em janeiro de 2019 no GIMPS (Great Internet Mersenne Prime Search). A grande curiosidade é sobre a existência de números perfeitos ímpares, pois dentre os 51 números perfeitos descobertos até agora não há nenhum ímpar. Basta notar que todos são múltiplos de uma potência de 2.

Pitágoras era fascinado pelos ricos padrões e as propriedades dos números perfeitos e respeitava sua sutileza. À primeira vista, o conceito de perfeição é relativamente simples de entender, no entanto os antigos gregos foram incapazes de sondar alguns aspectos fundamentais deste assunto. Por exemplo, embora exista uma grande quantidade de números cujos divisores somados são uma unidade a menos do que o próprio número, ou seja, são ligeiramente deficientes, parecem não existir números ligeiramente excessivos. Os gregos foram incapazes de descobrir quaisquer números cujos divisores somados excedem em uma unidade o número original e não conseguem entender por que isso acontece. E para aumentar sua frustração também não conseguiram provar que tais números não existiam. É compreensível que a aparente falta de números levemente excessivos não tivesse nenhuma utilidade prática, entretanto era um problema que poderia revelar a natureza dos números e, portanto, valeria a pena estudar. Tais enigmas intrigaram a Irmandade Pitagórica, e dois mil e quinhentos anos depois os matemáticos ainda são incapazes de provar que não existem números ligeiramente excessivos (SINGH, 2008, p. 34).

Outros números de grande importância para a teoria dos números e aritmética, que Pitágoras junto a sua escola descobriu, foram os "números primos", que são os números que possuem apenas dois divisores: o próprio número e a unidade. $O$ único número primo par é o 2 e há uma infinidade de números primos ímpares. Os "números amigos" são outra descoberta de Pitágoras. Números amigos são dois números cuja soma dos divisores próprios de um deles é igual ao outro. O exemplo encontrado por Pitágoras foi o par 220 e 284. Note que os divisores próprios de 220 são 1, 2, 4, 5, 10, 11, 20, 22, 44, 55 e 110, que apresentam soma igual a 284. O mesmo acontece com 284 cujos divisores próprios são 1, 2, 4, 71 e 142, que apresentam soma igual a 220. Outros pares de números amigos foram descobertos por Pierre Fermat em 1636 e por Leonard Euler em 1747. 
A descoberta dos números irracionais também é creditada a irmandade pitagórica. Um de seus membros, ao analisar um triângulo retângulo com catetos congruentes medindo uma unidade, notou que não havia nenhum número racional que fornecesse a medida da hipotenusa, pois $x^{2}=1^{2}+1^{2}$, ou seja, $x^{2}=2$ e não existe número racional que elevado ao quadrado resulte no inteiro 2. Logo existiria pelo menos um número que não se encaixava na crença dos pitagóricos de que tudo poderia ser resolvido com os números inteiros ou com a divisão de inteiros. Logo este problema, que era considerado por Pitágoras como um erro, foi encoberto, sendo revelado muito tempo depois. Há uma lenda de que Pitágoras teria condenado o descobridor deste fato à morte por afogamento, forçando todos a manterem o segredo.

A irmandade pitagórica tinha um símbolo que era o pentágono regular estrelado, simplesmente chamado de pentagrama, que nada mais é do que o pentágono regular com suas cinco diagonais como mostra a figura abaixo:

Figura 1. Pentágono regular estrelado

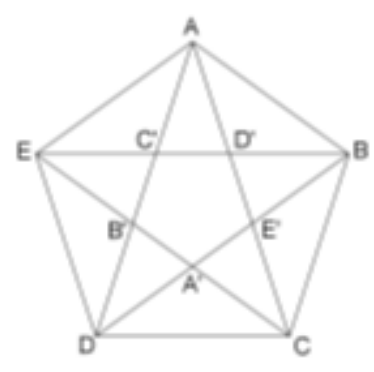

Fonte: Os autores.

O símbolo da escola pitagórica é uma figura intrigante, justamente porque ela é formada por muitas curiosidades. A primeira delas é que suas diagonais se intersectam formando outro pentágono regular. De acordo com a Figura 1, o pentágono A'B'C'D'E'. Outra curiosidade é que cada um dos pontos A', B', C', D' e E' dividem suas diagonais em segmentos com medidas diferentes de tal modo que "a razão da medida de toda a diagonal para a medida do maior segmento gerado é igual à razão da medida deste para a medida do menor segmento gerado". Tomando a diagonal $\overline{A D}$ como exemplo, temos que $\frac{A D}{C^{\prime} D}=\frac{C^{\prime} D}{A C^{\prime}}$ . Os gregos conheciam esta divisão como "divisão de um segmento em média e extrema razão". Atualmente ela é conhecida como "secção áurea" de um segmento, denominação criada por Kepler (1571 - 1630). 
Pitágoras também foi o responsável pela formalização da escala musical que usamos hoje.

\begin{abstract}
O instrumento mais importante da antiga música helênica era o tetracórdio, ou lira de quatro cordas. Antes de Pitágoras, os músicos tinham percebido que certas notas, quando soavam juntas, criavam um efeito agradável e afinavam suas liras de modo que ao tocarem duas cordas pudessem produzir tal harmonia. Contudo, os antigos músicos não compreendiam por que certas notas, em especial, eram harmônicas e não tinham nenhum meio preciso de afinar seus instrumentos. Eles afinavam suas liras pelo ouvido, até conseguirem um estado de harmonia - um processo que Platão chamava de torturar as cravelhas (SINGH, 2008, p. 35).
\end{abstract}

Pitágoras observou que quando os comprimentos das cordas estavam em algumas proporções, elas soavam de forma harmônica. Ele notou que se uma corda produzia uma nota qualquer, outra corda com o dobro do tamanho produziria a mesma nota em uma oitava abaixo. Este mesmo princípio é utilizado hoje em harpas e pianos. Pitágoras formalizou as notas musicais que conhecemos da seguinte forma: dada uma corda que produzia um Dó, uma corda com o dobro do comprimento levaria a um Dó uma oitava abaixo e de forma ascendente, uma corda com 16:9 de seu tamanho produziria um Ré, 8:5 para Mi, 3:2 para Fá, 4:3 para Sol, 6:5 para Lá e 16:15 para Si.

Todas estas descobertas fizeram com que a escola pitagórica ganhasse notoriedade na Grécia antiga, porém junto com este prestígio muita inveja também era atraída.

Da mesma maneira que os pitagóricos conseguiram ascensão política, os inimigos surgiram. Um dos senhores mais ricos de Crotona, chamado Cilon, empreendeu um ataque a uma casa onde se reuniam os pitagóricos e muitos foram assassinados. Pitágoras foi para Tarento e daí, para Metaponto, onde perdeu a vida, aproximadamente, em 500 a.C. (CYRINO, 2006, p. 52).

Pitágoras e os pitagóricos foram pessoas que deixaram um legado matemático e filosófico muito grande, porém esta história importante da Matemática é envolta em muitas lendas, pelo fato de muitas de suas descobertas ficarem em segredo, além da perda da maioria dos documentos. Há uma lenda que diz que, neste ataque aos pitagóricos, toda a casa foi incendiada, queimando os registros de Pitágoras e sua escola.

\title{
O teorema de Pitágoras
}

Um triângulo retângulo é um triângulo que possui um de seus ângulos internos medindo $90^{\circ}$. O maior lado de um triângulo retângulo, chamado de hipotenusa (palavra que tem origem no grego "hypoteínousa", cujo significado é "contrário a ..."), é justamente o lado 
oposto ao ângulo reto e os outros dois lados que formam o ângulo reto são chamados de catetos (palavra que tem origem no grego "Kathetos" cujo significado é "que cai perpendicular").

O teorema de Pitágoras é uma relação entre os comprimentos dos lados de um triângulo retângulo, e pode ser enunciado da seguinte forma: "Dado um triângulo retângulo, o quadrado do comprimento da hipotenusa é igual à soma dos quadrados dos comprimentos dos catetos".

Figura 2: Triângulo retângulo

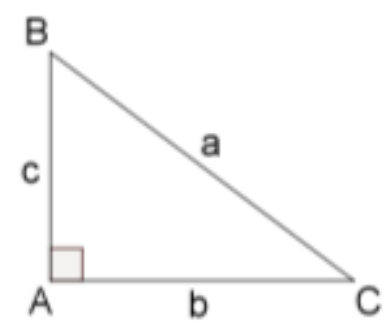

Fonte: Os autores.

Com a notação dada na figura acima, temos a seguinte identidade: $a^{2}=b^{2}+c^{2}$. Note que o teorema de Pitágoras relaciona os comprimentos dos lados de um triângulo retângulo, porém esta identidade também pode ser utilizada para relacionar as áreas dos quadrados gerados a partir dos lados do mesmo triângulo retângulo. Ou seja, as áreas dos quadrados gerados pela hipotenusa e catetos são respectivamente $a^{2}, b^{2}$ e $c^{2}$.

Figura 3: O teorema de Pitágoras por comparação de áreas

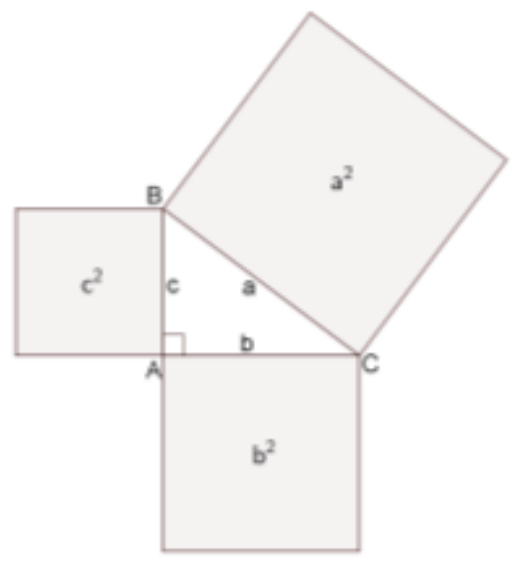

Fonte: Os autores. 
Esta relação, identificada como teorema de Pitágoras, era conhecida por muitos povos anteriores ao Pitágoras. Ela tem este nome, pois é muito provável que Pitágoras ou seus discípulos da escola pitagórica a tenham demonstrado pela primeira vez. Como já dito anteriormente, os egípcios usavam um triângulo retângulo para refazerem as marcações de ângulos retos na terra. Porém os povos antigos, que tiveram algum contato com o triângulo retângulo e com a relação entre seus lados, não tinham o interesse de saber o porquê dessa relação, assim como de outras que provavelmente conheciam. Para eles, era suficiente o benefício que as relações os traziam, ou seja, o interesse era único e exclusivo nas aplicações e não nas demonstrações.

O fato é que esta relação entre o comprimento dos três lados do triângulo retângulo gera um trio de números, que é chamado de "terno pitagórico". Muitos desses ternos eram conhecidos pelos povos anteriores a Pitágoras, como mostram alguns documentos. Um deles é o "Plimpton 322", que é uma tábua babilônica feita com argila e de escrita cuneiforme (tipo de escrita feita com um instrumento em forma de cunha) datada de 1800 a.C.. Esta tábua está localizada hoje na coleção da Universidade de Columbia, e contém uma tabela com quinze linhas de ternos pitagóricos.

A tábua era evidentemente uma tabela trigonométrica ou um auxílio didático para a regra de calcular hipotenusas de triângulos retângulos. Ela não contém variáveis, e parece que sua intenção era divulgar a regra por meio de uma lista de exemplos (CREASE, 2011, p. 18).

$\mathrm{Na}$ Índia antiga, a regra provada por Pitágoras também era conhecida e utilizada. Algumas aplicações estão registradas nos "Sulbasutras", documentos que fazem parte do maior corpo de textos do período védico (1500 a.C. - 500 a.C.). Eles são as únicas fontes de conhecimento da matemática indiana. O "Zhou Bi Suan", nome que significa "a clássica aritmética da Gnomon e os caminhos do céu circular" (Gnomon é a lâmina triangular do relógio de sol), é o texto chinês de Astronomia e Matemática mais antigo, provavelmente feito no I século a.C., que apresenta o conhecimento gerado no período da dinastia Zhou (1046 a.C. - 256 a.C). Neste texto há uma gravura que pode ser considerada parte do que seria a primeira prova geométrica do que viria a ser o teorema de Pitágoras. Em todos estes textos, há a aparição de ternos pitagóricos ou gravuras com triângulos retângulos, porém em nenhum deles se apresenta uma demonstração algébrica ou geométrica completa do teorema. 
A tábua babilônica, os Sulbasutras indianos e o Zhou Bi chinês exibem o conhecimento da regra aplicada a algum outro propósito: educação, no caso da Plimpton 322; religião, no caso dos Sulbasutras; astronomia, no caso do Zhou Bi. Nestes e em outros textos antigos, a regra é apresentada sem uma justificativa explícita, mas como um meio para descobrir distâncias e conferir resultados, algumas vezes com certo grau de formalismo (CREASE, 2011, p. 19).

Outro acontecimento curioso é do terno pitagórico mais conhecido (3, 4 e 5) aparecer na proporção da grande pirâmide do Egito. Normalmente este terno de números era utilizado para encontrar ângulos retos e deve ter sido esse mesmo o intuito, com o objetivo de posicionar o vértice da pirâmide conforme a figura abaixo.

Figura 4: Pirâmide e o terno pitagórico 3, 4 e 5

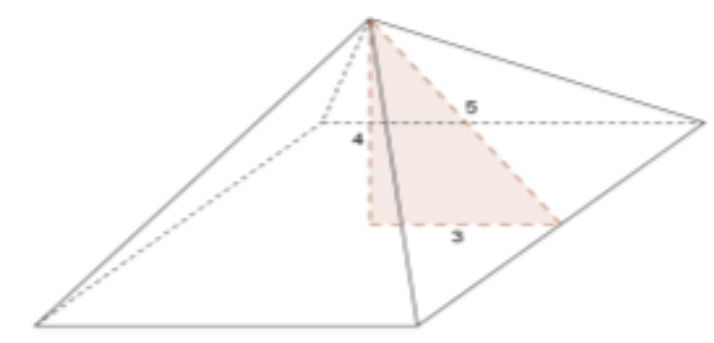

Fonte: Os autores.

Provar uma regra é muito diferente de apenas conhecê-la. Uma prova demonstra a validade geral de um resultado baseada em princípios fundamentais - ela é sua própria motivação, não visa a nenhum resultado prático e está menos preocupada com o resultado em si do que com o método utilizado para atingí-lo; mais preocupada com o processo pelo qual passamos a confiar nela. Uma prova reconta a jornada pela qual passamos a conhecer uma equação. Fornecer a prova de uma regra requer uma perspectiva matemática diferente de apenas enunciar a regra (CREASE, 2011, p. 20).

Provavelmente Pitágoras foi o primeiro a demonstrar este teorema, que era tão utilizado pelos povos antigos, na Índia, China, Egito e Babilônia. Não se sabe qual é exatamente a demonstração feita por Pitágoras. Acredita-se que tenha sido uma demonstração geométrica, usando comparação de áreas. Então vamos à provável demonstração feita por Pitágoras.

Dado um triângulo retângulo com catetos medindo " $a$ " e " $b$ "; e hipotenusa medindo "c", deseja-se mostrar que $c^{2}=a^{2}+b^{2}$.

Seja um quadrado com lados medindo " $a+b$ ". Constrói-se um quadrado de lados medindo " $c$ " conforme a figura abaixo: 


\section{ENSIN@UFMS 2021}

Figura 5: Primeiro quadrado com lado medindo " $a+b$ "

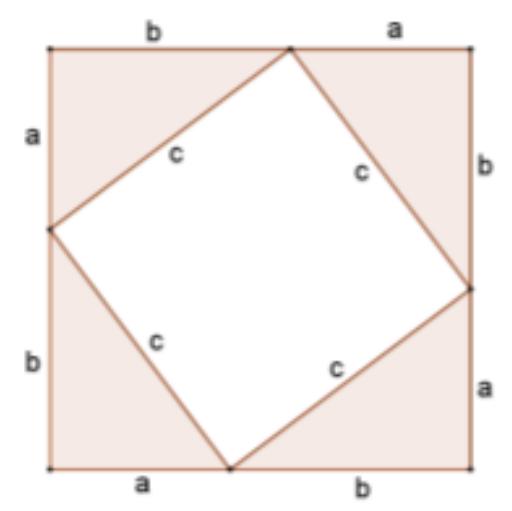

Fonte: Os autores.

Sabe-se que o quadrilátero de lado medindo " $c$ " é um quadrado, pois os ângulos agudos de cada triângulo retângulo são complementares.

Agora, pode-se desmembrar o quadrado acima em quatro triângulos retângulos congruentes e um quadrado. Utilizando os quatro triângulos congruentes é possível remontar o quadrado com lado medindo " $a+b$ " com outra configuração, conforme a figura abaixo:

Figura 6: Segundo quadrado com lado medindo " $a+b$ "

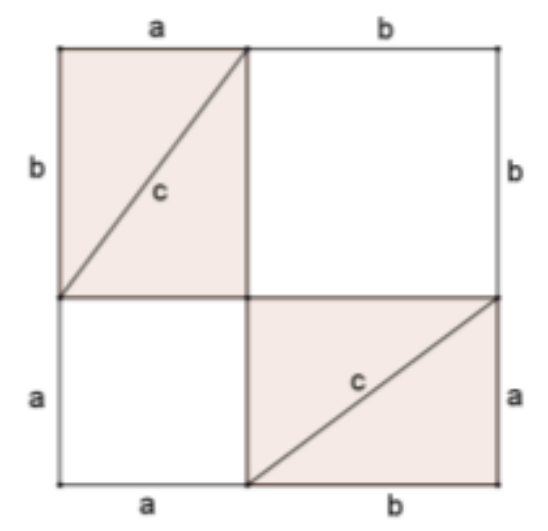

Fonte: Os autores.

Note que nesta nova figura, o quadrado de lados medindo " $a+b$ " é composto por seis polígonos: os mesmos quatro triângulos congruentes, um quadrado com lados medindo " $a$ " e um quadrado com lados medindo " $b$ ". Desta forma, fazendo uma comparação entre as duas figuras, temos que a área original não foi alterada pela nova composição. Isto 
indica que a área do quadrado de lado medindo " $c$ " da primeira figura é igual à soma das áreas dos quadrados com lados medindo " $a$ " e " $b$ " da segunda figura. Ou seja, $c^{2}=a^{2}+b^{2}$.

\section{Demonstrações do teorema de Pitágoras}

O teorema de Pitágoras é um dos mais famosos teoremas da história da Matemática, pois, além de toda a lenda que o envolve, ele possui muitas demonstrações distintas. Comparado aos outros tantos teoremas da Matemática, sem dúvida, o teorema de Pitágoras é o que possui o maior número de demonstrações. Estas demonstrações são, em sua grande maioria, geométricas, mas também existem demonstrações de caráter algébrico.

Em 1927 (quando já era professor universitário), Loomis publicou $A$ proposição pitagórica, livro contendo 230 provas; em 1940, então aos 87 anos, Loomis publicou uma segunda edição, com 370 provas. [...] A última frase de sua segunda edição é: "E ainda não chegamos ao fim".

Loomis estava certo; não era o fim. O site Guinness World Records, sob o título "Maior quantidade de provas do teorema de Pitágoras", recentemente apontou um grego que diz ter descoberto 520 provas distintas. (CREASE, 2011, p. 24 e 25).

Apresentamos cinco demonstrações distintas do teorema de Pitágoras, sendo duas delas feitas por pessoas de grande reconhecimento científico e na sociedade, uma de amplo conhecimento acadêmico, uma de caráter geométrico, mas com propriedades aritméticas em seu desenvolvimento e a última que é bastante curiosa.

I) Demonstração de Euclides: Em "Os elementos" de Euclides, livro I, a proposição 47 é o teorema de Pitágoras acompanhado de sua demonstração. Observe como o teorema é enunciado: Em um triângulo retângulo, o quadrado sobre o lado oposto ao ângulo reto é igual à soma dos quadrados sobre os lados que formam o ângulo reto.

Demonstração: Euclides iniciou sua demonstração construindo três quadrados, a partir dos lados de um triângulo $A B C$, reto em $A$ e construindo um segmento de reta perpendicular a hipotenusa com extremidades em $A$ e $K$, conforme a figura abaixo: 
Figura 7: Demonstração de Euclides

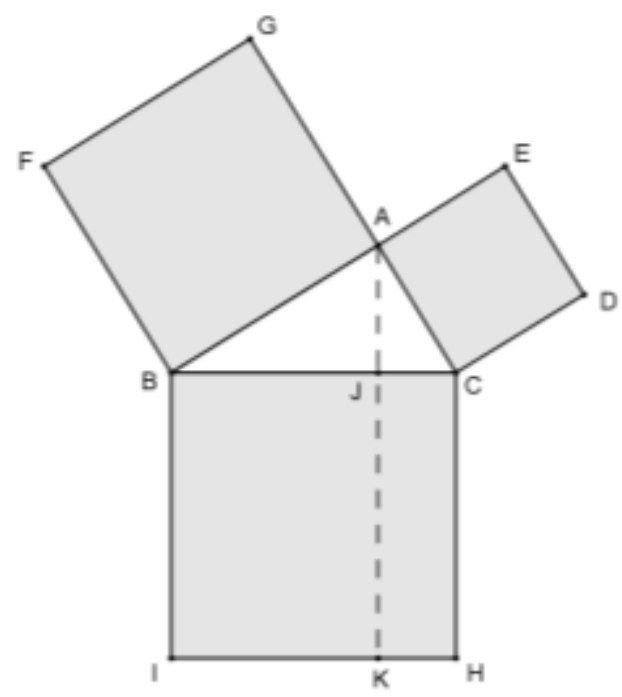

Fonte: Os autores.

O objetivo de Euclides era mostrar que a soma das áreas dos quadrados menores é igual à área do quadrado maior. Para isso, Euclides traçou os segmentos $\overline{A H}$ e $\overline{B D}$ (Figura 11), construindo os triângulos $A C H$ e $D C B$ que são congruentes; pois $\overline{A C} \equiv \overline{D C}, A C H \equiv D C B$ (já que ambos são iguais a $\operatorname{med}(A C B)+90^{\circ}$ ) e $\overline{C H} \equiv \overline{C B}$, o que nos leva ao caso L.A.L. de congruência entre triângulos, que Euclides havia demonstrado na proposição 4 do mesmo livro. Observe a figura a seguir:

Figura 8: Congruência na demonstração de Euclides

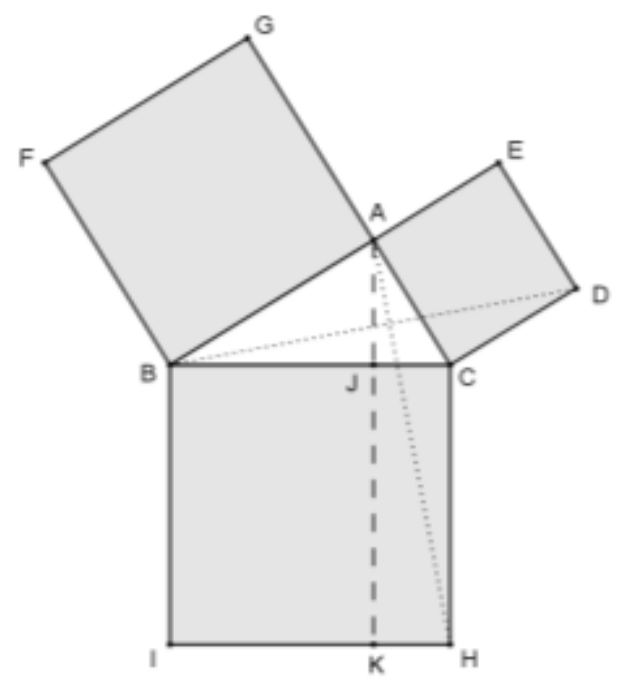

Fonte: Os autores. 
Porém, o triângulo $A C H$ e o retângulo $J K H C$ possuem a mesma base $\overline{C H}$ e a mesma altura $\overline{C J}$ (observe que os dois polígonos estão entre as paralelas $A^{\prime} K$ e $C^{\prime} H$ ). Na proposição 41, também do livro I, Euclides já demonstrara que um triângulo com a mesma base e altura de um quadrilátero, também possui metade de sua área. Assim, a área do triângulo $A C H$ é a metade da área do retângulo $J K H C$. Da mesma forma, a área do triângulo $D C B$ é metade da área do quadrado $A C D E$, pois ambos possuem base $\overline{C D}$ e altura $\overline{C A}$ (observe que os dois polígonos estão entre as paralelas $B^{\prime} E$ e $C D$ ).

Como os triângulos $A C H$ e $D C B$ possuem a mesma área, pois são congruentes, os quadriláteros $J K C H$ e $A C D E$ também possuem áreas iguais, já que suas áreas são o dobro da área dos triângulos $A C H$ e $D C B$, respectivamente.

Analogamente, os quadriláteros $J K I B$ e $A B F G$ têm áreas iguais. Mas, a área do quadrado $B C H I$ é a soma das áreas dos quadriláteros $J K I B$ e $J K H C$. Ou seja, a área do quadrado maior é igual à soma das áreas dos quadrados menores.

II) Demonstração de Leonardo da Vinci: Dado um triângulo retângulo $A B C$, reto em $A$, a ideia de Leonardo da Vinci foi construir um quadrado a partir de cada lado do triângulo e mostrar que a soma das áreas dos quadrados menores é igual à área do quadrado maior, assim como fez Euclides. Para isso, além dos quadrados, Leonardo utilizou dois triângulos retângulos congruentes ao triângulo original, conforme a figura abaixo:

Figura 9: Demonstração de Leonardo da Vinci

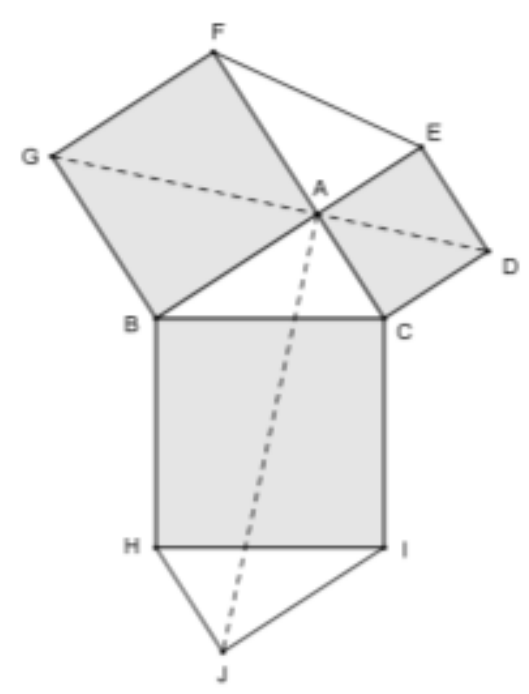

Fonte: Os autores. 
Note que o segmento $\overline{D G}$ particiona o hexágono $B C D E F G$ em dois quadriláteros congruentes, pois $G B C D$ é o simétrico do quadrilátero GFED em relação ao próprio segmento $\overline{D G}$. Já o hexágono $A B H J I C$ é dividido em dois quadriláteros congruentes pelo segmento $\overline{A J}$, observe que o quadrilátero $A B H J$ é a rotação em $180^{\circ}$ do quadrilátero JICA. Porém estes quatro quadriláteros são todos congruentes entre si. Para isso basta perceber a congruência entre os quadriláteros $A B H J$ e $G B C D$, pois $\overline{A B} \equiv \overline{G B}, A B H \equiv G B C$ (já que ambos são iguais a $\operatorname{med}(A B C)+90^{\circ}$ ), $\overline{B H} \equiv \overline{B C}, B \hat{H} J \equiv B C D$ (já que ambos são iguais a $\left.\operatorname{med}(B C A)+90^{\circ}\right)$ e $\overline{H J} \equiv \overline{C D}$.

Como os quatro quadriláteros são congruentes, então suas áreas são iguais. Assim como as áreas dos hexágonos $B C D E F G$ e $A B H J I C$. Mas o primeiro hexágono é composto por dois triângulos retângulos congruentes ao $A B C$ e pelos quadrados menores. Já 0 segundo hexágono, é composto por dois triângulos retângulos congruentes ao $A B C$ e pelo quadrado maior. Estas duas afirmações garantem que a soma das áreas dos quadrados menores é igual à área do quadrado maior.

III) Demonstração por semelhança de triângulos: Esta é a demonstração mais difundida nos livros didáticos, por isso a mais conhecida nos dias de hoje. Esta demonstração é a mais utilizada, porque usa um conteúdo de grande importância, que é a semelhança de triângulos.

Dado um triângulo retângulo $A B C$, reto em $A$, constrói-se a altura relativa à hipotenusa, que a divide em dois segmentos que são as projeções dos catetos sobre a hipotenusa, denotadas na figura abaixo como " $m$ " e " $n$ ".

Figura 10: Demonstração por semelhança de triângulos

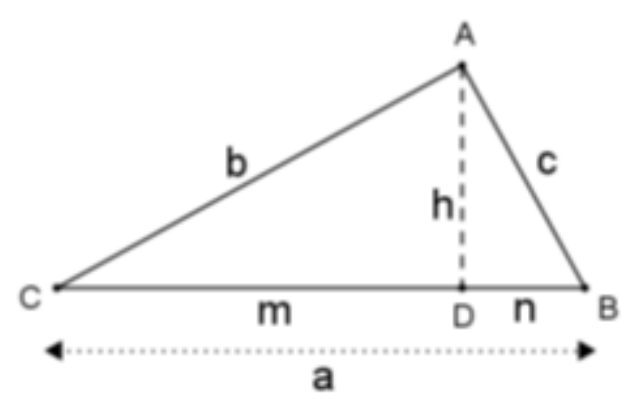

Fonte: Os autores. 
Observe que os triângulos $D B A$ e $D A C$, retos em $D$, são semelhantes ao triângulo $A B C$, reto em $A$. Utilizando a semelhança entre $D B A$ e $A B C$, tem-se que $\frac{c}{n}=\frac{a}{c}$. Aplicando a propriedade fundamental da proporção tem-se que $c^{2}=n \cdot a$. Com a semelhança entre os triângulos $D A C$ e $A B C$, tem-se que $\frac{b}{m}=\frac{a}{b}$, que leva a relação $b^{2}=m \cdot a$. Somando as relações obtidas das duas semelhanças, chega-se a $b^{2}+c^{2}=m \cdot a+n \cdot a=(m+n) \cdot a=$ $a \cdot a=a^{2}$, que é a relação do teorema de Pitágoras.

IV) Demonstração utilizando o teorema das cordas: Para esta demonstração do teorema de Pitágoras, precisaremos do teorema das cordas. Segue abaixo a definição de uma corda e uma demonstração do teorema das cordas.

Corda: É um segmento de reta cujas extremidades pertencem a uma mesma circunferência. Um exemplo é o "diâmetro da circunferência", nome dado a uma corda que passe pelo centro da circunferência.

Teorema das cordas: Se duas cordas se encontram, então o produto das medidas dos dois segmentos determinados em uma delas é igual ao produto das medidas dos segmentos determinados na outra.

Sejam $\overline{A B}$ e $\overline{C D}$ cordas que se encontram em um ponto $P$ no círculo, conforme a figura abaixo:

Figura 11: Demonstração do teorema das cordas

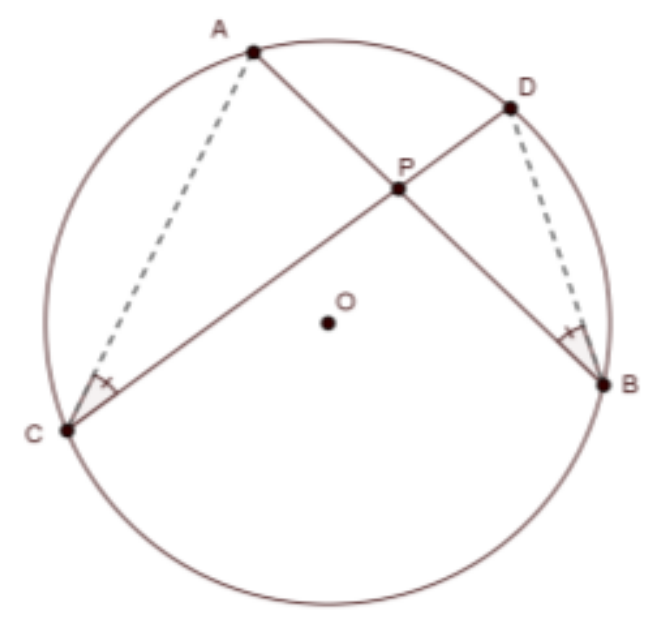

Fonte: Os autores. 
Construindo os segmentos $\overline{A C}$ e $\overline{B D}$, nota-se que os triângulos $A C P$ e $D B P$ são semelhantes pelo caso A.A.A., pois $A C D D A B D$ (já que ambos são ângulos inscritos no mesmo arco $A(D)$ e $A P C \equiv B P D$ (ângulos opostos pelo vértice). Por semelhança, tem-se $\frac{A P}{P D}=\frac{C P}{P B}$.

Com este resultado vamos demonstrar o teorema de Pitágoras da seguinte forma:

Dado um triângulo $A B C$, reto em $A$, constrói-se uma circunferência com centro em $B$ e raio $\overline{B C}$, conforme a figura abaixo:

Figura 12: Demonstração utilizando o teorema das cordas

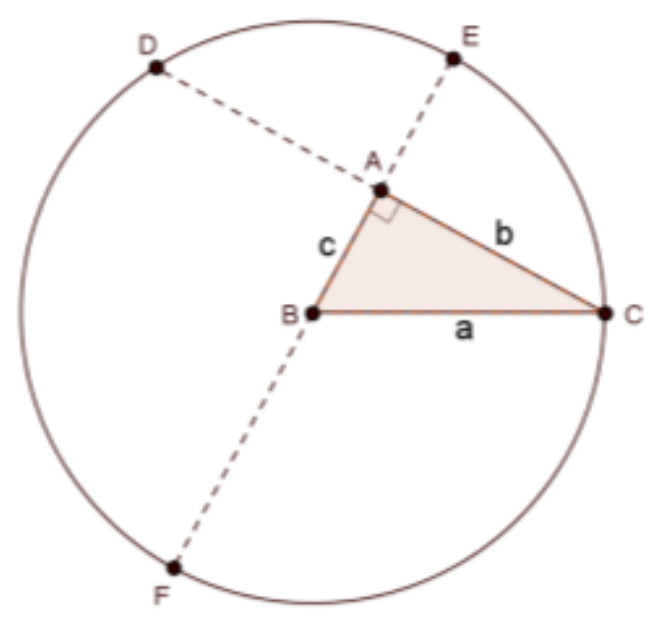

Fonte: Os autores.

Observe que ao prolongarem-se os catetos $\overline{A C}$ e $\overline{A B}$ obtemos as cordas $\overline{E F}$ e $\overline{C D}$, que se intersectam perpendicularmente no ponto $A$, sendo $\overline{E F}$ o diâmetro da circunferência. Desta forma a corda $\overline{C D}$ é intersectada em seu ponto médio, sendo $A D=b$. Basta observar que o triângulo $B C D$ é isósceles de base $\overline{C D}$ e que $\overline{B A}$ é sua altura. Note que $B F=a$ (raio da circunferência) e $A E=a-c$. Utilizando o teorema das cordas, tem-se $A C \cdot A D=A E$. $A F$, ou seja $b \cdot b=(a-c) \cdot(a+c)$. Resolvendo o produto notável, encontra-se $b^{2}=a^{2}-$ $c^{2}$. Ou equivalentemente, $a^{2}=b^{2}+c^{2}$, que é a identidade do teorema de Pitágoras, pois " $a$ " é a medida da hipotenusa e, " $b$ " e "c" são as medidas dos catetos do triângulo $A B C$.

V) demonstração de Bhaskara: O matemático indiano Bhaskara (1114 - 1185) foi um que encontrou uma demonstração do teorema de Pitágoras baseada apenas na 
observação de duas figuras. Diz a lenda, que Bhaskara desenhou as duas figuras abaixo e escreveu somente uma pequena palavra em sua argumentação: Olha!

Figura 13: Desenho feito por Bhaskara
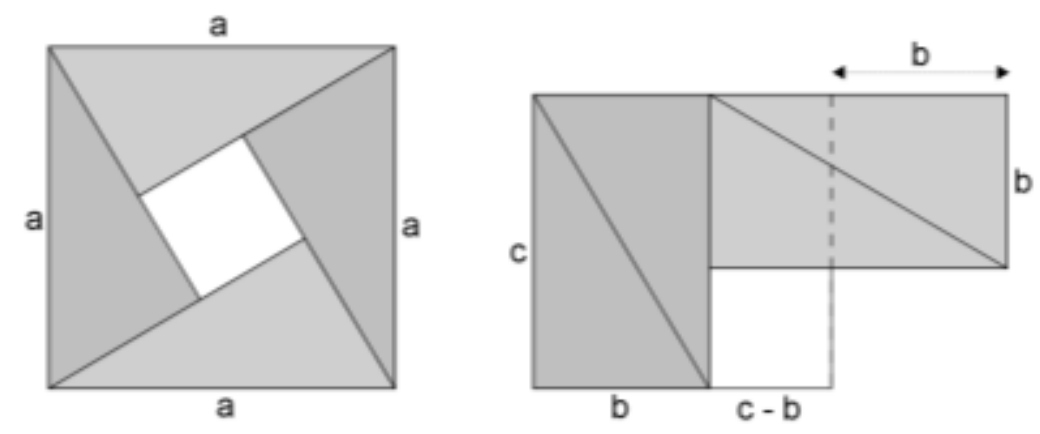

Fonte: Os autores.

A intenção de Bhaskara foi construir uma figura com área medindo $a^{2}$ e outra figura com área medindo $b^{2}+c^{2}$, onde $a, b$ e $c$ são, respectivamente, a hipotenusa e os catetos dos triângulos retângulos.

\title{
Proposta didática de abordagem do tema "teorema de Pitágoras"
}

Neste trabalho, pode-se conhecer parte da história sobre Pitágoras, a escola pitagórica e o teorema de Pitágoras. Este fragmento da história da Matemática é riquíssimo em lendas e curiosidades que podem encantar qualquer aluno. Por isso, seria importante que os professores de Matemática dessem devida atenção à abordagem histórica deste tema nas salas de aula. Ou seja, quando forem ensinar o teorema de Pitágoras, que a abordagem seja mais rica em conteúdo histórico.

\begin{abstract}
A História da Matemática pode oferecer uma importante contribuição ao processo de ensino e aprendizagem dessa área do conhecimento. Ao revelar a Matemática como uma criação humana, ao mostrar necessidades e preocupações de diferentes culturas, em diferentes momentos históricos, ao estabelecer comparações entre os conceitos e processos matemáticos do passado e do presente, o professor cria condições para que o aluno desenvolva atitudes e valores mais favoráveis diante desse conhecimento (PCN's Ensino Fundamental - Ciências da natureza, matemática e suas tecnologias - MEC, 1998, p. 42).
\end{abstract}

A proposta feita por este trabalho é que ao se ensinar o teorema de Pitágoras, a abordagem mais eficaz, mais profícua, mais interessante seja a da descoberta. Que o aluno ao ser iniciado nesta viagem no tempo, seja instigado a desenvolver uma curiosidade para 
buscar novas informações históricas. Isto facilita 0 aprendizado e incentiva 0 compartilhamento de conhecimento entre os alunos da turma.

Outro fator de grande importância é que o teorema de Pitágoras possui um número muito grande de demonstrações distintas. Então, é interessante que o professor e o livro didático apresentem diferentes demonstrações e, mais do que isso, incentive seus alunos a demonstrar o teorema de Pitágoras de diferentes formas. Crie uma conjectura e peça a seus alunos que trabalhem no tema, forneça algumas ferramentas e incentive $o$ aluno a busca pela elaboração da prova formal. Isto já pode ser feito no 9o ano do ensino fundamental, como diz o fragmento dos "Parâmetros Curriculares Nacionais" abaixo:

Apesar da força de convencimento para os alunos que possam ter esses
experimentos com material concreto ou com a medição de um desenho, eles não
se constituem provas matemáticas. Ainda que essas experiências possam ser
aceitas como provas no terceiro ciclo, é necessário, no quarto ciclo, que as
observações do material concreto sejam elementos desencadeadores de
conjecturas e processos que levem às justificativas mais formais (PCN's Ensino
fundamental - Ciências da natureza, matemática e suas tecnologias - MEC, 1998,
p. 127).

O que normalmente acontece é que as demonstrações aparecem timidamente nos livros didáticos do ensino fundamental e, praticamente, desaparecem nos livros do ensino médio. E, se o professor não apresentar as demonstrações aos alunos nesta fase da vida acadêmica, os que ingressarem em carreiras da área de Ciências Exatas, serão apresentados às provas e demonstrações na universidade. Isto pode ser traumático para o aluno, pois parece que a Matemática estudada na educação básica é completamente diferente da Matemática da educação superior. Se no ensino fundamental o aluno já pode ser apresentado às demonstrações e provas, no ensino médio existe a oportunidade de aprofundamento dos alunos nestas mesmas demonstrações apresentadas no ensino fundamental. Apresentamos a seguir a orientação dada pelos Parâmetros Curriculares Nacionais para o ensino médio:

O ensino de Geometria no ensino fundamental está estruturado para propiciar uma primeira reflexão dos alunos através da experimentação e de deduções informais sobre as propriedades relativas a lados, ângulos e diagonais de polígonos, bem como o estudo de congruência e semelhança de figuras planas. Para alcançar um maior desenvolvimento do raciocínio lógico, é necessário que no ensino médio haja um aprofundamento dessas idéias no sentido de que o aluno possa conhecer um sistema dedutivo, analisando o significado de postulados e teoremas e o valor de uma demonstração para fatos que lhe são familiares ( $P C N+$ Ensino médio Ciências da natureza, matemática e suas tecnologias - MEC, 2007, p. 123 e 124). 
A última proposta deste trabalho é que o ensino do teorema de Pitágoras seja aplicado em situações reais. Os alunos podem ser convocados a verificarem a perpendicularidade das paredes da sala de aula usando o teorema de Pitágoras, mais especificamente o triângulo com lados medindo $30 \mathrm{~cm}$ e $40 \mathrm{~cm}$. Caso o terceiro lado deste triângulo meça $50 \mathrm{~cm}$, então as paredes serão perpendiculares. Quando se aplica o saber teórico a uma situação próxima do aluno, ele deixa de ser teórico e passa e ser prático, despertando o interesse do aluno pelo tema. O teorema de Pitágoras é um exemplo de conhecimento que pode ser aplicado a inúmeras situações do cotidiano, basta que os professores, e também os autores de livros didáticos, busquem estas aplicações, a fim de apresentar o conteúdo de maneira mais interessante e agradável.

\section{Considerações finais}

Após a apresentação de uma parte histórica e demonstrações, pode-se concluir que o teorema de Pitágoras possui um encanto praticamente inexplicável. Este teorema é o mais demonstrado de toda a Matemática, sendo essas demonstrações de todos os tipos e características. Apesar disso, o teorema tem um enunciado simples que se traduz em uma identidade pequena e direta.

Teorema e história tão fascinantes merecem atenção especial dos livros didáticos de Matemática, que apresentam a parte histórica de maneira muito breve e despretensiosa. A apresentação da parte histórica deve ter a intenção de motivar o leitor a se interessar pelo teorema de Pitágoras, buscando mais fontes e sendo instigado a dissecar o tema (mesmo que esta tarefa seja difícil). Assim, o aluno teria a real dimensão da importância deste teorema para a história da Matemática e para o desenvolvimento da Geometria que temos nos dias de hoje. O desenvolvimento da parte histórica de qualquer conteúdo matemático mostra para os alunos que a Matemática é uma ciência construída pelos homens ao longo de muito tempo, com muito esforço e estudo. Isto, de certa forma, humaniza o conhecimento e traz o aluno para mais próximo da Matemática. Como o teorema de Pitágoras possui uma história bela em detalhes e curiosidades, é um desperdício não utilizá-la para motivar os alunos a gostarem um pouco mais de Matemática.

As demonstrações do teorema são itens que ficam de fora em alguns livros, que apresentam o teorema sem qualquer justificativa formal. 
Matemática pode ser brevemente apresentada como sendo composta por conjecturas, histórias, demonstrações e aplicações. Por essa razão, nossa sugestão é que nada disso fique de fora dos livros didáticos e da sala de aula!

\section{Bibliografia}

BOYER, C. B. História da matemática. 2. ed. São Paulo: Blücher, 1996.

CREASE, R. P. As grandes equações: a história das fórmulas matemáticas mais importantes e os cientistas que as criaram. Rio de Janeiro: Zahar, 2011.

CYRINO, H. F. F. Matemática \& Gregos. São Paulo: Editora Átomo, 2006.

PARÂMETROS CURRICULARES NACIONAIS. Ensino Fundamental - Ciências da natureza, matemática e suas tecnologias - MEC, 1998.

PARÂMETROS CURRICULARES NACIONAIS MAIS. Ensino médio - Ciências da natureza, matemática e suas tecnologias - MEC, 2007.

SINGH, S. O Último Teorema de Fermat: a história do enigma que confundiu as maiores mentes do mundo durante 358 anos. 13. ed. Rio de Janeiro: Record, 2008.

\section{NOTAS}

\section{IDENTIFICAÇÃO DO TEXTO}

O presente texto é uma adaptação do trabalho intitulado Sobre o Teorema de Pitágoras, dissertação de Mestrado Profissional em Matemática em Rede Nacional, apresentada na Universidade Federal Fluminense em 26 de março de 2013 e elaborado sob a orientação da Professora Dra. Cecília de Souza Fernandez.

\section{IDENTIFICAÇÃO DE AUTORIA}

Cecília de Souza Fernandez. PhD em Matemática (Kent State University, Ohio, USA). Professora Titular. Universidade Federal Fluminense (UFF). Instituto de Matemática e Estatística. Departamento de Análise. Niterói, RJ, Brasil.

E-mail: ceciliafernandez@id.uff.br

(iD) https://orcid.org/0000-0001-6410-5117

Weverton Magno Ferreira de Castro. Mestre pelo Programa PROFMAT na Universidade Federal Fluminense (UFF). Professor do Ensino Básico, Técnico e Tecnológico. Instituto Federal de Educação, Ciência e Tecnologia do Rio de Janeiro (IFRJ), Niterói, RJ, Brasil.

E-mail: weverton.castro@ifrj.edu.br

(1) https://orcid.org/0000-0002-5849-9305

\section{AGRADECIMENTOS}

Agradecemos a Universidade Federal Fluminense por ter abrigado o programa PROFMAT e propiciar uma formação de qualidade para professores do Ensino Básico. Fica nosso agradecimento a Sociedade Brasileira de Matemática pelo projeto desse programa que vem fortalecendo o ensino de Matemática no nosso país. 


\section{FINANCIAMENTO}

O presente trabalho foi realizado com apoio da Coordenação de Aperfeiçoamento de Pessoal de Nível Superior - Brasil (CAPES) - Código de Financiamento 001.

\section{CONSENTIMENTO DE USO DE IMAGEM}

Não se aplica.

\section{APROVAÇÃO DE COMITÊ DE ÉTICA EM PESQUISA}

Não se aplica.

\section{LICENÇA DE USO}

Autores mantêm os direitos autorais e concedem à revista ENSIN@ UFMS - ISSN 2525-7056 o direito de primeira publicação, com o trabalho simultaneamente licenciado sob a Licença Creative Commons Attribution (CC BY-NC-SA 4.0), que permite compartilhar e adaptar o trabalho, para fins não comerciais, reconhecendo a autoria do texto e publicação inicial neste periódico, desde que adotem a mesma licença, compartilhar igual.

\section{EDITORES}

Patricia Helena Mirandola Garcia, Eugenia Brunilda Opazo Uribe, Gerson dos Santos Farias.

\section{HISTÓRICO}

Recebido em: 30/08/2021 - Aprovado em: 06/11/2021 - Publicado em: 15/12/2021.

\section{COMO CITAR}

FERNANDEZ, C. S; CASTRO, W. M. F. Uma Proposta Didática para o Ensino do Teorema de Pitágoras. Revista ENSIN@ UFMS, Três Lagoas, v. 2, número especial, p. 44-66. 2021. 